Article

\title{
Protein Profiling Gastric Cancer and Neighboring Control Tissues Using High-Content Antibody Microarrays
}

\author{
Martin Sill ${ }^{1}$, Christoph Schröder ${ }^{2,3}$, Ying Shen ${ }^{4}$, Aseel Marzoq ${ }^{2}$, Radovan Komel ${ }^{5}$, \\ Jörg D. Hoheisel ${ }^{2}$, Henrik Nienhüser ${ }^{4}$, Thomas Schmidt ${ }^{4}$ and Damjana Kastelic ${ }^{2, *}$ \\ 1 Division of Biostatistics, Deutsches Krebsforschungszentrum (DKFZ), Im Neuenheimer Feld 581, \\ 69120 Heidelberg, Germany; m.sill@dkfz.de \\ 2 Division of Functional Genome Analysis, Deutsches Krebsforschungszentrum (DKFZ), \\ Im Neuenheimer Feld 580, 69120 Heidelberg, Germany; schroeder@sciomics.de (C.S.); \\ a.marzoq@dkfz.de (A.M.); j.hoheisel@dkfz.de (J.D.H.) \\ 3 Sciomics GmbH, In Neuenheimer Feld 583, 69120 Heidelberg, Germany \\ 4 Department of General, Visceral and Transplantation Surgery, University Clinic Heidelberg, \\ Im Neuenheimer Feld 110, 69120 Heidelberg, Germany; shenying_0624@outlook.com (Y.S.); \\ Henrik.Nienhueser@med.uni-heidelberg.de (H.N.); Thomas1.schmidt@med.uni-Heidelberg.de (T.S.) \\ 5 Medical Faculty, University of Ljubljana, Vrazov Trg 2, 1000 Ljubljana, Slovenia; komel@mf.uni-lj.si \\ * Correspondence: kastelic.dkfz@gmail.com; Tel.: +49-6221-42-4679
}

Academic Editors: Carl A. K. Borrebaeck, Christer Wingren and Ulrika Andreasson Axelsson Received: 18 April 2016; Accepted: 13 June 2016; Published: 8 July 2016

\begin{abstract}
In this study, protein profiling was performed on gastric cancer tissue samples in order to identify proteins that could be utilized for an effective diagnosis of this highly heterogeneous disease and as targets for therapeutic approaches. To this end, 16 pairs of postoperative gastric adenocarcinomas and adjacent non-cancerous control tissues were analyzed on microarrays that contain 813 antibodies targeting 724 proteins. Only 17 proteins were found to be differentially regulated, with much fewer molecules than the numbers usually identified in studies comparing tumor to healthy control tissues. Insulin-like growth factor-binding protein 7 (IGFBP7), S100 calcium binding protein A9 (S100A9), interleukin-10 (IL-10) and mucin 6 (MUC6) exhibited the most profound variations. For an evaluation of the proteins' capacity for discriminating gastric cancer, a Receiver Operating Characteristic curve analysis was performed, yielding an accuracy (area under the curve) value of $89.2 \%$ for distinguishing tumor from non-tumorous tissue. For confirmation, immunohistological analyses were done on tissue slices prepared from another cohort of patients with gastric cancer. The utility of the 17 marker proteins, and particularly the four molecules with the highest specificity for gastric adenocarcinoma, is discussed for them to act as candidates for diagnosis, even in serum, and targets for therapeutic approaches.
\end{abstract}

Keywords: gastric cancer; adenocarcinoma; affinity based proteomics; antibody microarrays; biomarker identification

\section{Introduction}

Gastric cancer is currently the second leading cause of cancer-related death worldwide [1]. The median survival time is 24 months and the overall five-year survival rate is between $10 \%$ and $30 \%$. Mortality has remained unchanged over the past three decades. Curative therapy commonly involves surgical resection of the complete stomach or part of it. However, the response is quite poor [2]. This can be attributed to an extended asymptomatic period and the resulting difficulty in detecting early stages of the disease. Early diagnosis improves the long-term survival of patients substantially. Also, 
a single therapeutic target—human epidermal growth factor receptor 2 (HER2)—is currently used for gastric cancer treatment [3]. The identification of potential target molecules of high specificity is therefore urgently required.

Gastric cancer is a heterogeneous disease, a fact that is reflected by its clinical and pathological classification. The heterogeneity is responsible for an individually widely diverse clinical outcome [4]. The vast majority (95\%) of gastric cancer cases are adenocarcinomas [5]. They arise from secretory epithelia in the inner lining of gastric mucosa, which can be subdivided into intestinal and diffuse (as well as indeterminate) types according to the Lauren classification [6]. Based on tumor invasiveness and differentiation, the adenocarcinomas are graded into four subtypes, T1 to T4. An alternative classification system of the World Health Organization divides gastric cancer into papillary, tubular, mucinous and poorly cohesive (as well as mixed) carcinomas [7]. Most of the adenocarcinomas diagnosed belong to the advanced cancer stages $\mathrm{T} 3$ and $\mathrm{T} 4$ and are accompanied by lymph node metastases. Without tumor resection, they exhibit a median survival period of merely five months [8].

Currently, gastric adenocarcinomas are often diagnosed on the basis of the localization of the tumor cells and their invasiveness. There are very few molecular biomarkers available to grade gastric cancer according to its invasiveness [8]. Growth factor receptors such as EGFR, c-met and ERBB2 have been used as predictors of later stages of malignancy, but with a high degree of uncertainty. CCL18 combined with particular T-cell receptors is employed as a prognostic indicator in early stages of gastric cancer [9]. A recent study performed by The Cancer Genome Atlas Research Network (TCGA) [10] revealed four classes of gastric cancer based on a combined analysis of somatic copy number, whole genome sequencing, DNA methylation profiling, mRNA and miRNA sequencing as well as results from reverse phase protein arrays. A new molecular classification was suggested, dividing gastric cancer into four subtypes: (i) tumors positive for Epstein-Barr virus, which display recurrent PIK3CA mutations; (ii) extreme DNA hypermethylation and amplification of JAK2, CD274 and PDCD1LG2; (iii) microsatellite unstable tumors, which show elevated mutation rates, including mutations of genes encoding targetable oncogenic signaling proteins; and (iv) tumors with chromosomal instability, which show marked aneuploidy and focal amplification of receptor tyrosine kinases. This classification scheme underlines the complexity of gastric cancer molecular fingerprints. The high degree of gastric cancer heterogeneity emphasizes the urgent need for robust molecular classifiers as well as new potential targets for therapy, which are common between tumors and exhibit a high degree of specificity for cancer.

As indicated by the TCGA study, omics-technologies can act as excellent tools for the identification of biomarkers. DNA microarrays and, more recently, sequencing were widely employed for screening studies on biomarkers at genomic and transcript levels. However, inconsistencies in the validation of biomarkers identified by various genomic approaches have been reported. This fact as well as substantial advances in technology led recently to the strong emergence of proteome analyses for biomarker discovery. Rather than analyzing the basic information encoded in the DNA sequence, proteome analyses study molecular end products that are actually functional and thus responsible for many vital cellular activities. While the basic molecular reasons for the occurrence of tumors may vary widely, particular functional aspects are likely to be common nevertheless. Also for this reason, proteins are the molecule class that is targeted by most cancer drugs.

Affinity-based analysis processes are widely used in studies that aim at the discovery of protein biomarkers, irrespective of the actual assay format. Mass spectrometry or Western blotting, for example, take advantage of antibodies for purification or detection, respectively. Antibody microarrays are the most complex platform for affinity-based protein analysis. During the last 15 years, they have developed enormously by optimization of many experimental factors and facets-from efficient antibody attachment and blocking procedures, via improved sample isolation and labeling protocols, to incubation and detection processes that allow quantitative measurements. Meanwhile, they permit a highly sensitive, accurate and reproducible detection in a highly multiplexed manner of proteins isolated from any type of specimen, even if available sample quantities are very small [11-13]. The 
number of targets that have been studied in an individual analysis varies from several dozens to thousands [14]. Technically, there is basically no upper limit in the number of molecules that can be dealt with in parallel. The current most limiting factor is the availability of appropriate antibodies, although there are some 2.37 million binders listed in the database antibodypedia (version 9 of 23 March 2016; www.antibodypedia.com). With respect to quality assessment, elaborate procedures have been established which permit antibody microarray analyses to be performed with an accuracy and reproducibility that meet the standards for application in cancer diagnosis and prognosis in a clinical setting (e.g., $[15,16])$. Read-out sensitivities down to attomolar concentration or even single-molecule detection have been reported $[17,18]$.

As an immunoassay, antibody microarrays are close to assay formats that are well established and accepted in clinical diagnostics. Thus, they represent an effective tool for biomarker discovery and also warrant a relatively quick and simple translation of results into a format that is applicable in clinical practice. We have used high-content antibody microarrays to profile gastric tumor and adjacent non-tumorous tissue samples. In most studies, the control samples are isolated from another group of tissue donors, thus adding another degree of complexity. The approach taken here should allow the identification of biomarkers of the highest possible specificity in tumor tissue; ignoring personal differences, for example, such molecules could be most useful for common diagnostic and therapeutic purposes. Immunohistochemistry was then applied to confirm the variations in the abundance of proteins, which were found to be the most discriminative.

\section{Materials and Methods}

\subsection{Protein Isolation and Labeling}

Sixteen primary tumors from patients diagnosed with gastric adenocarcinoma, who had not received any treatment prior to tumor resection, were obtained at the Department of Gastroenterology of the University Medical Centre in Ljubljana. During the resection process, also adjacent tissue surrounding each tumor was removed. Written informed consent had been given by the patients and sample collection had been approved by the institutional ethics committee. The tissue pairs were immediately snap-frozen in liquid nitrogen and stored at $-80{ }^{\circ} \mathrm{C}$ until use. Total protein extract was prepared and fluorescently labeled as described in detail previously [19]. Briefly, the tissues were pulverized while still frozen in the presence of liquid nitrogen. The material was lysed for $30 \mathrm{~min}$ on ice in 10 volumes of lysis buffer composed of $50 \mathrm{mM}$ carbonate buffer ( $\mathrm{pH}$ 8.5), $20 \%$ glycerol, $1.0 \mathrm{mM} \mathrm{MgCl}_{2}, 5.0 \mathrm{mM}$ EDTA, $1.0 \mathrm{mM}$ phenylmethanesulfonyl fluoride, $1.0 \mathrm{U} / \mathrm{mL}$ benzonase (Merck Biosciences, Schwalbach, Germany), Halt protease and phosphatase inhibitor mixture (Thermo Scientific, Bonn, Germany), $0.5 \%$ Nonidet P-40 substitute, $1.0 \%$ cholic acid, $0.25 \%$ n-dodecyl-maltoside (GenaXXon Bioscience, Ulm, Germany), and 0.5\% amidosulfobetaine- 14 . Cell debris was pelleted by $20 \mathrm{~min}$ centrifugation at $4{ }^{\circ} \mathrm{C}$ and 13,000 rpm. The protein concentration was determined with the Bicinchoninic Acid Protein Assay Reagent (BCA) kit (Thermo Scientific) according to the manufacturer's protocol. Before labeling, each protein extract was adjusted to a concentration of $1 \mathrm{mg} / \mathrm{mL}$.

Each sample of extracted proteins was separately fluorescently labeled by reaction with the NHS-esters of the dyes DY-549 and DY-649 (Dyomics, Dresden, Germany) at a molar dye/protein ratio of 1:18, assuming that the average weight of a protein is $60 \mathrm{kDa}$. Labeling was carried out in lysis buffer in the dark at $4{ }^{\circ} \mathrm{C}$ for $1 \mathrm{~h}$. Then, unreacted dye was quenched by adding $2.5 \%$ hydroxylamine for $30 \mathrm{~min}$ at $4{ }^{\circ} \mathrm{C}$. The non-incorporated and inactivated dye molecules were removed with a zeba spin-desalting column with a cut-off of $3.5 \mathrm{kDa}$ (Thermo Scientific). The labeled protein samples were stored frozen at $-20^{\circ} \mathrm{C}$ in the presence of protease inhibitor cocktail (Roche Diagnostics, Mannheim, Germany). To exclude any bias potentially introduced by the fluorescent dyes, the labels were swapped between tumor and control samples. 


\subsection{Microarray Production}

The antibody microarray used for this study contained 813 antibodies directed against 724 cancer-related proteins [15]. The antibodies had been selected based on previous transcription profiles obtained from different cancer entities as well as a literature and database search on cancer-related proteins. The antibodies $(1 \mathrm{mg} / \mathrm{mL})$ were printed in quadruplicates on epoxysilane-coated slides (Nexterion-E, Schott, Jena, Germany) using the contact printer (MicroGrid-2, Biorobotics, Cambridge, UK) with SMP3B pins (Telechem, Sunnyvale, CA, USA) at a humidity of $40 \%$ to $45 \%$ in $50 \mathrm{mM}$ carbonate buffer ( $\mathrm{pH} 8.5$ ), containing $0.005 \%$ Tween-20,5\% trehalose and $1 \mathrm{mM}$ magnesium chloride. After spotting, the slides were allowed to equilibrate at a humidity of $40 \%$ to $45 \%$ overnight and then stored at $4{ }^{\circ} \mathrm{C}$ in dry and dark conditions until use.

\subsection{Microarray Incubation, Scanning, and Image Processing}

Sample incubation on the antibody microarrays was performed on a HS4800 hybridization station (Tecan, Männedorf, Switzerland). First, slides were allowed to settle at room temperature for about $30 \mathrm{~min}$ before being washed with phosphate buffered saline (PBST: $137 \mathrm{mM} \mathrm{NaCl}, 12 \mathrm{mM}$ phosphate, $2.7 \mathrm{mM} \mathrm{KCl}, \mathrm{pH} 7.4$ with $0.1 \%$ Tween-20). After blocking with a casein-based blocking solution (Candor Biosciences, Weißensberg, Germany) for $1 \mathrm{~h}$ at room temperature, $5 \mu \mathrm{g}$ of each labeled protein sample was taken up in blocking buffer containing $1 \%$ Triton and $1 \times$ protease inhibitor (Roche). Tumour samples were mixed with the extracts isolated from the respective adjacent non-tumorous tissue but labeled with a different fluorescent dye. Incubation on the microarrays was for $8 \mathrm{~h}$ at $4{ }^{\circ} \mathrm{C}$. Then, the microarrays were washed with PBST, rinsed with water and dried.

\subsection{Data Analysis and Sample Classification}

Scanning of the slides was performed with a PowerScanner (Tecan) at a resolution of $10 \mu \mathrm{m}$, maintaining laser power and the photomultiplier constant. Relevant parameters, such as the concordance of the two colour detection channels, were carefully validated throughout. Spot segmentation was performed with GenePix Pro 6.0 software package (Molecular Devices, Sunnyvale, CA, USA). The complete data set is made available as Supplemental Table 1. The spot signals were analysed with R-Bioconductor using a one-factorial linear model fitted with LIMMA package, which resulted in a $t$-test based on moderated statistics. Adjusted $p$-values were calculated [20]; protein variations with $p$-values less than 0.05 were considered significant. There was not cut-off on the basis of the degree of variation; the only measure was significance. After sample normalization, an unsupervised hierarchical clustering was performed to check for technical and handling artifacts in the data. In order to show how the single-channel, $\log _{2}$ expression signals of the arrays can be used for discriminating between tumor and non-tumorous tissue, a Random Forest classifier [20] was trained using tissue type as response variable and the $\log _{2}$ protein expression signals of IGFBP7, S100A9, IL-10 and MUC6 as explanatory variables. This model was validated with 500 bootstrap iterations, resulting in (out-of-bag) a receiver operating characteristic curve and a corresponding area under the curve (AUC) value. For training and validating the classifier, the R-packages randomForest [21] and caret [22] were applied, using the default settings for classification.

\subsection{Immunohistochemistry}

Immunohistochemistry analysis was performed on paraffin sections of five tissue samples. Deparaffinization and rehydration was performed on the sections via Roticlear and a diluted series of alcohol. Thereafter, the samples were boiled twice in $10 \mathrm{mM}$ citrate buffer for $10 \mathrm{~min}$. The slides were incubated at $4{ }^{\circ} \mathrm{C}$ overnight with a 1:100 dilution of primary antibodies IGFBP7 (ab171085, Abcam, Cambridge, UK) or S100A9 (ab24111, Abcam), respectively. Then, biotinylated secondary horse anti-mouse antibody (diluted 1:200; Vector, BA-2000) was added and incubated for $45 \mathrm{~min}$. For chromogen staining, streptavidin-HRP conjugate (1:100; Perkin Elmer, NEL700001KT) 
was added followed by biotinyl-tyramide. Antibody detection was performed by staining with $3,3^{\prime}$-diaminobenzidine $(\mathrm{DAB})$ and counterstaining with Haemalaun. After that, sections were rehydrated, fixed in ethanol/xylol and examined microscopically.

\section{Results}

Sixteen tumor tissue samples (Table 1) were surgically removed along with adjacent normal tissue from patients diagnosed with gastric adenocarcinoma. Total protein was extracted and analyzed on high content microarrays that consisted of 813 antibodies directed against 724 cancer-related proteins [15]. The sample pairs were labeled with two different fluorescent dyes and incubated together on the microarrays. After incubation and image acquisition, the data was normalized in order to account for differences in labeling efficiencies (Supplemental Table S1). The resulting signal intensities were subjected to an unsupervised clustering for the identification of any factor that may introduce a bias. The samples were found clustered according to the tissue type, suggesting that the clustering and segregation of normal and tumor samples were based on the differential abundance of proteins. No other factor, such as patient gender or patient age, date of surgery, order of protein preparation, labeling, array incubation or scanning, could be identified that may have influenced the clustering.

Table 1. Characteristics of the tumor samples.

\begin{tabular}{ccccccc}
\hline $\begin{array}{c}\text { Sample } \\
\text { Number }\end{array}$ & $\begin{array}{c}\text { Patient } \\
\text { Gender }\end{array}$ & Patient Age & $\begin{array}{c}\text { Location in } \\
\text { Stomach }\end{array}$ & $\begin{array}{c}\text { Tumour } \\
\text { Grade }\end{array}$ & $\begin{array}{c}\text { Lauren } \\
\text { Classification }\end{array}$ & $\begin{array}{c}\text { Number of Positive } \\
\text { Lymph Nodes }\end{array}$ \\
\hline 1 & Male & 84 & Corpus & 2 & Intestinal & 1 \\
2 & Male & 78 & Cardia & 2 & Intestinal & 0 \\
3 & Male & 60 & Cardia & 3 & Intestinal & 7 \\
4 & Male & 71 & Cardia & 3 & Diffuse & 5 \\
5 & Male & 61 & Antrum & 4 & Mixed & 8 \\
6 & Female & 72 & Antrum & 3 & Intestinal & 2 \\
7 & Female & 77 & Antrum & 3 & Intestinal & 0 \\
8 & Male & 72 & Antrum & 4 & Mixed & 0 \\
9 & Male & 85 & Antrum & 3 & Mixed & 0 \\
10 & Male & 56 & Corpus & 3 & Diffuse & 1 \\
11 & Male & 72 & Cardia & 3 & Intestinal & 21 \\
12 & Male & 53 & Corpus & 1 & Intestinal & 0 \\
13 & Male & 53 & Spread & 3 & Intestinal & 12 \\
14 & Male & 60 & Spread & 2 & Intestinal & 10 \\
15 & Male & 73 & Corpus & 3 & Intestinal & 12 \\
16 & Female & 69 & Spread & 3 & Intestinal & 16 \\
\hline
\end{tabular}

Of the 724 proteins against which there were antibodies on the array, only 17 proteins exhibited significantly differential abundance in the normal and tumor patient samples (Figure 1; Table 2). This number is surprisingly small, given the fact that the antibodies target mostly proteins, which are tumor-associated. In other analyses using the same platform, but comparing tumor versus healthy tissue (rather than non-tumorous material from next to the tumor), more than half of the proteins identified by the microarray antibodies always exhibited significant variation (e.g., [21,22]). One reason for the very few changes observed in gastric cancer could be its high degree of heterogeneity. While some proteins are differentially expressed in some tumors, only few proteins are similarly different in abundance in most or all samples. Another explanation could be that tissue that is located adjacent to the tumor is not that different molecularly to the actual tumor tissue, although no tumor cells are present. 


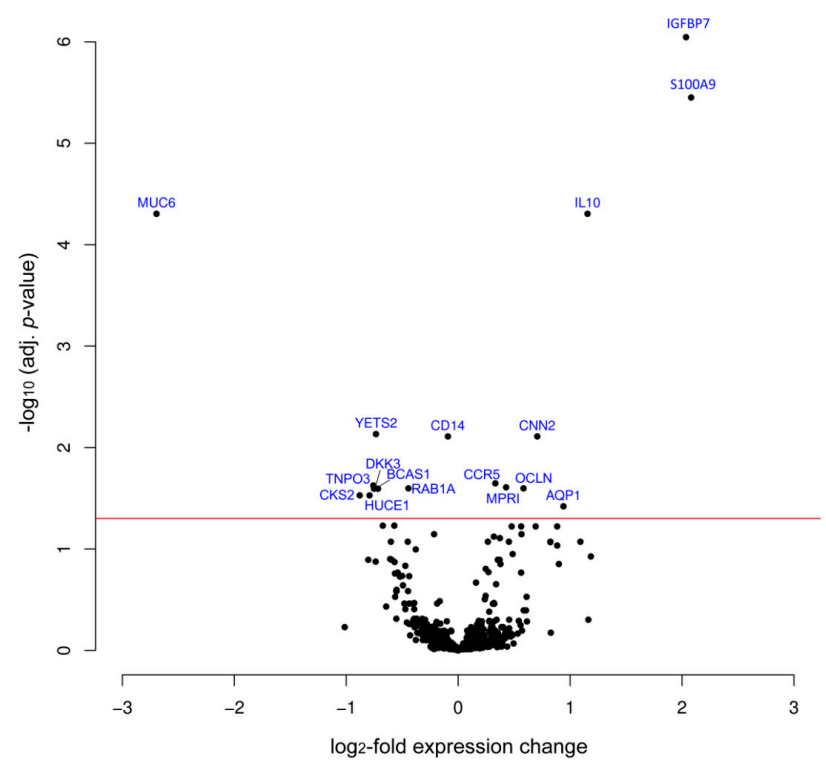

Figure 1. Volcano plot of protein expression variations. Protein expression in tumor and adjacent non-tumorous tissues was compared by means of the antibody microarray. The degree of variation and its significance are shown; the horizontal red line indicates an adjusted $p$-value of 0.05 . The black dots represent the proteins analyzed. While most of them fall below this threshold, 17 proteins exhibited significant differences. Some protein names are given; the complete list and the relevant data are shown in Table 2.

Table 2. Proteins that exhibited significant abundance variations between tumor and adjacent non-tumorous tissue.

\begin{tabular}{|c|c|c|c|c|}
\hline Protein & Variation $\log _{2} \mathrm{FC}$ & Adj. $p$-Value & Swissprot No. & Full Protein Name \\
\hline \multicolumn{5}{|c|}{ Proteins with most significant and strongest variation in expression } \\
\hline IGFBP7 & 2.04 & $8.99 \times 10^{-7}$ & Q16270 & Insulin-like growth factor-binding protein 7 \\
\hline S100A9 & 2.08 & $3.54 \times 10^{-6}$ & P06702 & S100 calcium binding protein A9 \\
\hline IL10 & 1.16 & $4.96 \times 10^{-5}$ & P22301 & Interleukin 10 \\
\hline MUC6 & -2.70 & $4.96 \times 10^{-5}$ & Q6W4X9 & Mucin 6 \\
\hline \multicolumn{5}{|c|}{ Other proteins of higher abundance in tumor } \\
\hline CNN2 & 0.71 & $7.77 \times 10^{-3}$ & Q99439 & Calponin-2 \\
\hline CCR5 & 0.33 & $2.26 \times 10^{-2}$ & P51681 & C-C chemokine receptor type 5 \\
\hline MPRI & 0.43 & $2.41 \times 10^{-4}$ & P11717 & Cation-independent mannose-6-phosphate receptor \\
\hline OCLN & 0.58 & $2.53 \times 10^{-2}$ & Q16625 & Occludin \\
\hline AQP1 & 0.94 & $3.80 \times 10^{-2}$ & P29972 & Aquaporin 1 \\
\hline \multicolumn{5}{|c|}{ Other proteins of lower abundance in tumor } \\
\hline YETS2 & -0.73 & $7.37 \times 10^{-3}$ & Q9ULM3 & YEATS domain-containing protein 2 \\
\hline CD14 & -0.09 & $1.07 \times 10^{-2}$ & P08571 & Monocyte differentiation antigen CD14 \\
\hline TNPO3 & -0.75 & $2.35 \times 10^{-2}$ & Q9Y5L0 & Transportin-3 \\
\hline BCAS1 & -0.72 & $2.53 \times 10^{-2}$ & O75363 & Breast carcinoma-amplified sequence 1 \\
\hline RAB1A & -0.44 & $2.53 \times 10^{-2}$ & P62820 & Ras-related protein Rab-1A \\
\hline DKK3 & -0.74 & $2.53 \times 10^{-2}$ & Q9UBP4 & Dickkopf-related protein 3 \\
\hline CKS2 & -0.88 & $2.97 \times 10^{-2}$ & P33552 & Cyclin-dependent kinases regulatory subunit 2 \\
\hline HUCE1 & -0.79 & $2.97 \times 10^{-2}$ & O43159 & Cerebral protein 1 \\
\hline
\end{tabular}

FC: Fold Change.

Within the group of 17 proteins, four exhibited the most pronounced expression difference: IGFBP7, S100A9 and IL-10 were found strongly up-regulated in tumor, while MUC6 was markedly less abundant compared to the reference tissue. The power of discriminating tumor and control samples was determined for the markers individually or in combination. The complete data set obtained from the microarray analysis yielded discrimination worse than that of the four proteins with the strongest variation alone. Their combined signature was found to perform best. A clustering based 
on the four markers led to a separation of the non-tumorous and tumor tissues (Figure 2). While yielding a good discrimination of tumor and non-tumorous samples, separation was not perfect. A particular example was the sample pair isolated from patient No. 12: both specimens behaved nearly identically as indicated by their clustering. They were the only sample pair isolated from a patient with a tumor grading of 1 . However, two other tumors-T-1 and T-11-were also not overly different from the average control tissue, although clearly distinct from their matched non-tumorous control sample. A principle component analysis produced a very similar picture. The addition of other marker molecules improved the separation of individual sample pairs. None of them was applicable to several pairs, however, and all of them decreased the overall performance.

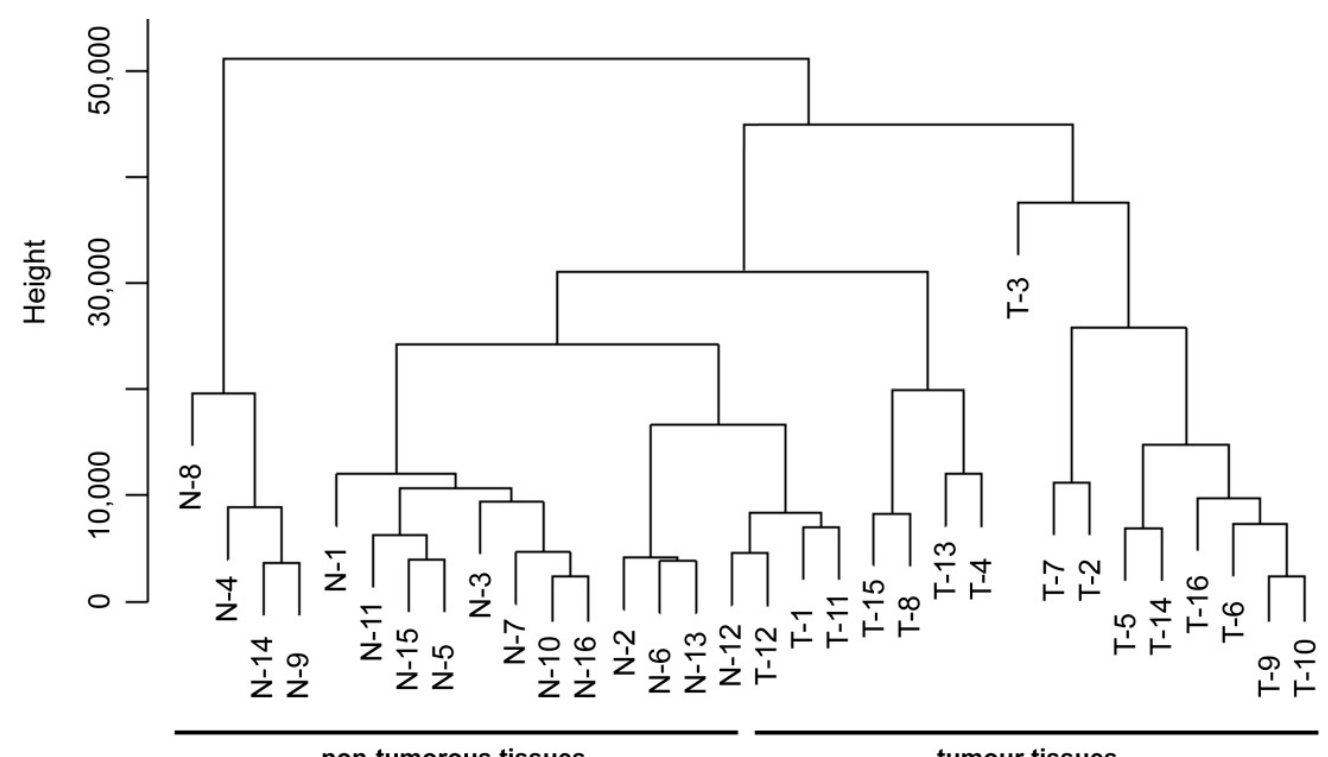

Age: 7271608584727361607756697872535353847273725371607778616069728556

$\begin{array}{lllllllllllllllll}\text { Tumour Grade: } & 1 & 2 & 3 & 3 & 4 & 3 & 3 & 3 & 3 & 2 & 4 & 2 & 3 & 3 & 3 & 3\end{array}$

Figure 2. Hierarchical clustering of the samples. Based on the expression of IGFBP7, S100A9, IL-10 and MUC6, the samples were subjected to hierarchical clustering. In most cases, there was a clear separation of non-tumorous and tumor samples. Below, for each sample, the age of the patients, from whom the tissues were isolated as well as the tumor grades are shown.

Apart from a variation between individual tumors, the distance of the non-tumorous tissues from the actual tumor location in the patient did differ. Unfortunately, no annotated information is available about this. Variation in the difference between tumors and controls could therefore be brought about by both biological as well as experimental heterogeneity. The accuracy of discriminating between tumor and adjacent non-tumorous tissue was evaluated more quantitatively by a Receiver Operating Characteristic curve analysis. An AUC value of 89.2\% was calculated (Figure 3) with the four marker molecules. For confirmation, immunohistochemistry analyses were performed on samples representing tumor or tissue obtained from healthy individuals. In all cases, the results were in agreement with the microarray data (e.g., Figure 4). 
a

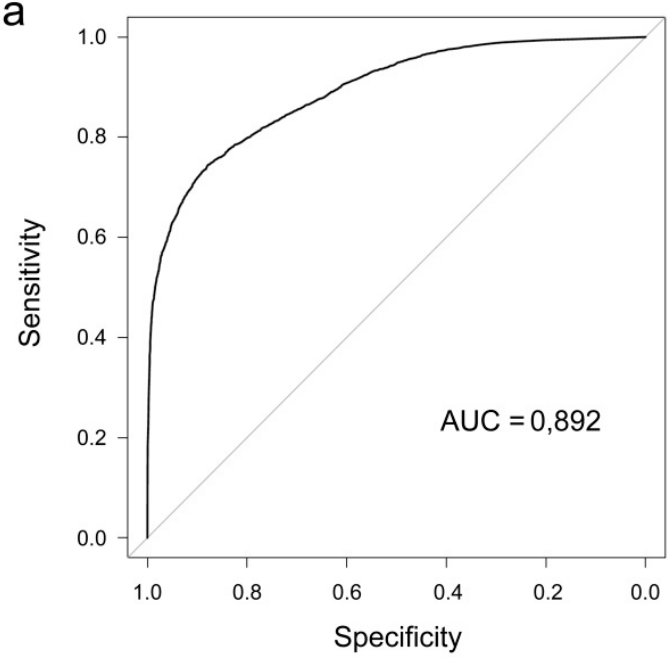

b

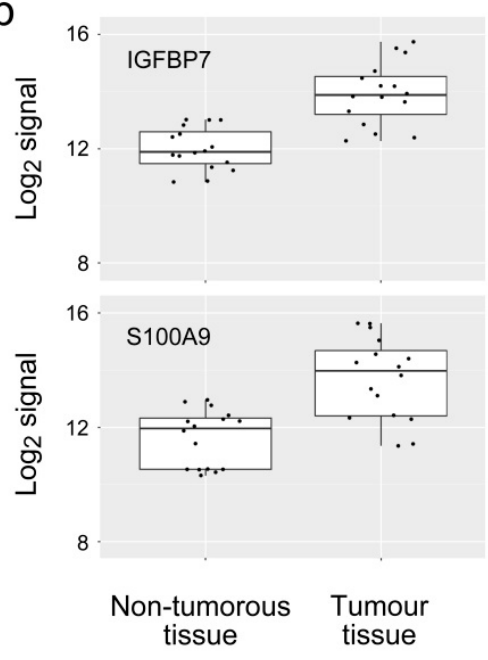

Figure 3. Accuracy of diagnosis. (a) The expression signature consisting of the expression of IGFBP7, S100A9, IL-10 and MUC6 was used for performing a Receiver Operating Characteristic curve analysis. The resulting area under the curve (AUC) was 89.2\%; (b) Box plots are shown for IGFBP7 and S100A9. The black dots stand for the individual measurements. The median as well as the upper and lower quartile are represented by the boxes.
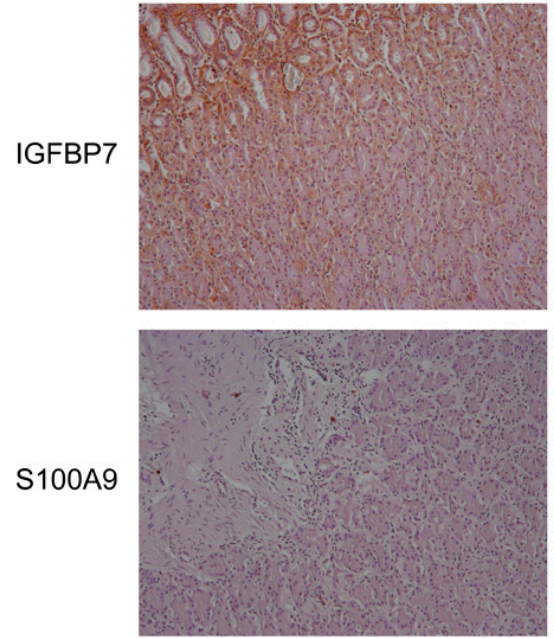

Non-tumorous tissue
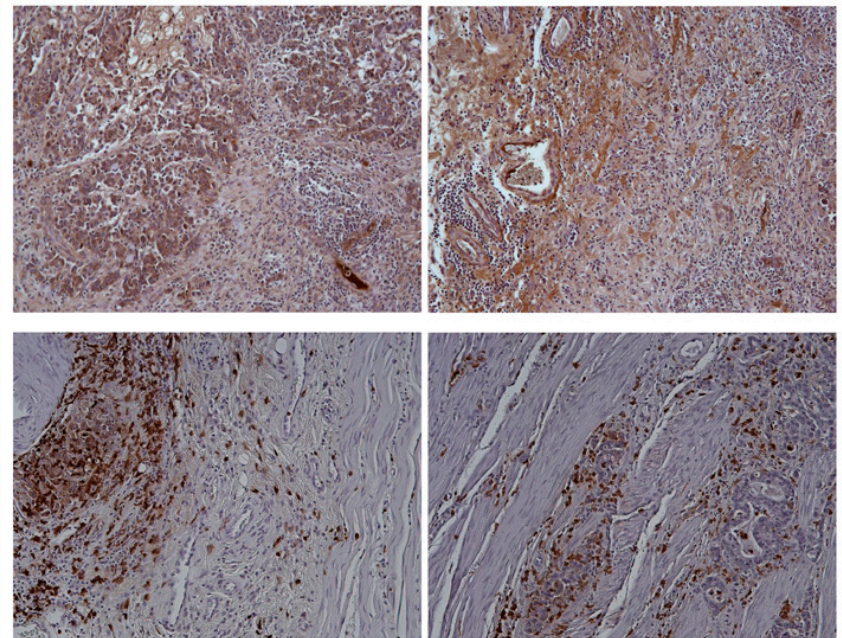

Tumour tissue

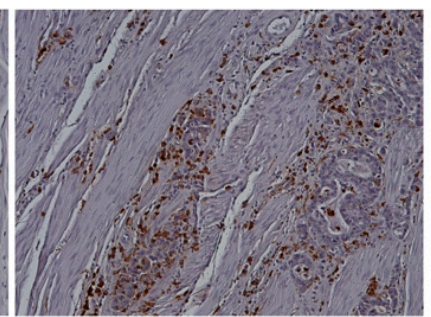

Tumour tissue

Figure 4. Typical results of immunohistochemical analyses. Marker molecules identified by the microarray analysis were validated and confirmed by immunohistochemistry (magnification $\times 100$ ) on tissue slices made from an independent set of tumor tissues and stomach samples from donors who had no cancer. Dark brown color is indicative of the presence of the respective protein.

\section{Discussion}

We focused our study on a comparison of gastric tumors and tissues close to them, rather than comparing stomach tissues from healthy donors and patients with gastric adenocarcinoma. Thereby, we aimed at avoiding any markers for effects such as inflammation, which are related to carcinogenesis but are not necessarily specific for cancer. While the number of samples was relatively small, the study design was such that identified markers had to be rather selective for tumor. The analysis yielded only relatively few proteins that exhibited significant differences in expression. While this was partly expected, the very low number came as a surprise. One reason could be a kind of cancer field defect, 
which is defined as a biological cancerization process in which the cells of relatively large areas beyond the actual tumor are exhibiting changes similar to the ones of the actual tumor [23-25]. As opposed to intercellular communication in the microenvironment, any molecules responsible for such a field defect had to be transported over relatively longer distances, since the non-tumorous tissue samples studied here had a distance to the tumor of up to one centimeter. Heterogeneity could be another explanation for the small number of differentially expressed proteins. While it should be less pronounced at the protein level, there could nevertheless be different protein combinations that result in a particular cancer phenotype. The number of common proteins would then be small. However, particularly these molecules may be essential for the tumor and may consequently be specific markers for diagnosis as well as proteins that are prime target candidates for therapy.

Among the few significantly different proteins were four molecules-IGFBP7, S100A9, IL-10 and MUC6 - that were set apart from the others by their degree of variation, which was both particularly strong and significant. In combination, they were able to differentiate tumor tissue from adjacent non-tumorous tissue with good accuracy. The immunohistochemical analysis indicates that the discriminative power may be even better when comparing healthy and tumor tissues. However, the number of samples analyzed was too small to validate this assumption sufficiently. Currently, we are in the process of studying this on a much larger number of patient and control samples. In this early-stage trial, we also aim at investigating the prognostic power of the biomarkers.

IGFBP7 was the molecule that exhibited the most significant variation. There have been conflicting reports about the correlation of its expression and tumor progression and survival. A recent study showed that an elevated IGFBP7 expression level in gastric cancer is associated with invasion, tumor progression and recurrence as well as poor survival [26]. As opposed to this, decreased IGFBP7 expression was also reported to be associated with tumor progression and poor survival in gastric cancer [27]. These controversial results could be explained by the fact that IGFBP7 is not homogeneously expressed [28] and that IGFBP7 signaling in stromal fibroblasts could override the tumor-suppressor function on epithelial cells.

S100A9 is a member of the S100 family and is overexpressed in various forms of cancer. It was reported to be up to five times more abundant in the plasma of patients with colorectal cancer, revealing its high diagnostic potential [29]. Immunohistochemistry analyses of gastric cancer samples showed that S100A9 was exclusively located in inflammatory cells, such as macrophages and neutrophils, infiltrating primary tumor tissues while all gastric cancer cells or cells adjacent to gastric mucosa did not express S100A9 [30]. Surprisingly, patients with a high S100A9 cell count had a favorable prognosis. S100A9 induces phosphorylation of MAPK and promotes the activation of NF- $\mathrm{B}$ [31]. Several studies have therefore examined a possible role in tumor cell migration and invasion [32,33]. The molecular mechanisms of S100A9 in gastric cancer invasion and migration are not fully understood, however.

IL-10 is a cytokine with immunosuppressive properties which is frequently elevated in the tumor microenvironment and correlates with a bad outcome [34]. It has been reported to be elevated in the blood of gastric cancer patients [35]. IL-10 represses the expression of inflammatory cytokines, such as TNF- $\alpha$, Interleukin- 6 and Interleukin-1- $\beta$, in macrophages. This role of IL-10 fostered the assumption that it undermines the immune response to cancer [36]. Upregulation of IL-10 has been suggested to be responsible for the persistence of inflammation and might facilitate tumor progression [37].

MUC6 is a highly glycosylated, secreted mucin that is involved in forming a physical barrier, which is critical for the protection of the epithelium. Its low expression was reported to contribute to the malignant transformation of gastric epithelial cells [38]. In general, mucins function by limiting the inflammatory responses at the interface with the environment. Deregulation of mucin production has therefore provided an important link between inflammation and cancer [39].

\section{Conclusions}

Overall, the particular set-up of our analysis - a comparison of tumors to non-tumorous tissues that had been directly adjacent to the tumors-identified a few markers which had been implicated 
in the carcinogenesis of gastric tumors before. More importantly, however, it ruled out a lot of other potential markers, in particular candidates that had been suggested on the basis of mRNA or protein profiling analyses comparing tissues from patients and healthy donors [40], which may not be tumor-specific, however. In addition, because of the pairwise evaluation of samples isolated from the same patient, the influence of variations between the individual donors could be ruled out. Instead, the analysis focused exclusively on the differences between tumor and non-tumorous tissues. Toward an application for diagnostic purposes, further studies need to be performed. In particular, abundance variations of these specific markers in plasma or serum of cancer patients would be of high utility. It is more likely that markers, which exhibit a strong expression increase, will be useful to such ends.

Supplementary Materials: The supplementary material is available online at http://www.mdpi.com/2076-3905/ 5/3/19/s1.

Acknowledgments: The authors wish to thank Joel Altmann, and Sascha Hinterkopf for their technical contributions and advice.

Author Contributions: Damjana Kastelic and Christoph Schröder conceived and designed the experiments; Damjana Kastelic performed the experiments; Damjana Kastelic, Christoph Schröder, Jörg D. Hoheisel and Martin Sill analyzed the data; Radovan Komel, Aseel Marzoq, Henrik Nienhüser and Thomas Schmidt contributed reagents and materials; Ying Shen performed immunohistochemistry, Damjana Kastelic and Jörg D. Hoheisel wrote the paper.

Conflicts of Interest: The authors declare no conflict of interest.

\section{References}

1. Karimi, P.; Islami, F.; Anandasabapathy, S.; Freedman, N.D.; Kamangar, F. Gastric cancer: Descriptive epidemiology, risk factors, screening, and prevention. Cancer Epidemiol. Biomark. Prev. 2014, 23, $700-713$. [CrossRef] [PubMed]

2. Dicken, B.J.; Bigam, D.L.; Cass, C.; Mackey, J.R.; Joy, A.A.; Hamilton, S.M. Gastric adenocarcinoma: Review and considerations for future directions. Ann. Surg. 2005, 241, 27-39. [PubMed]

3. Sanford, M. Trastuzumab: A review of its use in HER2-positive advanced gastric cancer. Drugs 2013, 73, 1605-1615. [CrossRef] [PubMed]

4. Pietrantonio, F.; de Braud, F.; da Prat, V.; Perrone, F.; Pierotti, M.A.; Gariboldi, M.; Fanetti, G.; Biondani, P.; Pellegrinelli, A.; Bossi, I.; et al. A review on biomarkers for prediction of treatment outcome in gastric cancer. Anticancer Res. 2013, 33, 1257-1266. [PubMed]

5. Brenner, H.; Rothenbacher, D.; Arndt, V. Epidemiology of stomach cancer. Methods Mol. Biol. 2009, 472, 467-477. [PubMed]

6. Lauren, P. The two histological main types of gastric carcinoma: Diffuse and so-called intestinal-type carcinoma. An attempt at a histo-clinical classification. Acta Pathol. Microbiol. Scand. 1965, 64, 31-49. [PubMed]

7. Flejou, J.F. Who classification of digestive tumors: The fourth edition. Ann. Pathol. 2011, 31, S27-S31. [PubMed]

8. Zheng, L.; Wang, L.; Ajani, J.; Xie, K. Molecular basis of gastric cancer development and progression. Gastric Cancer 2004, 7, 61-77. [CrossRef] [PubMed]

9. Leung, S.Y.; Yuen, S.T.; Chu, K.M.; Mathy, J.A.; Li, R.; Chan, A.S.; Law, S.; Wong, J.; Chen, X.; So, S. Expression profiling identifies chemokine (C-C motif) ligand 18 as an independent prognostic indicator in gastric cancer. Gastroenterology 2004, 127, 457-469. [CrossRef] [PubMed]

10. The Cancer Genome Atlas Research Network. Comprehensive molecular characterization of gastric adenocarcinoma. Nature 2014, 513, 202-209.

11. Betzen, C.; Alhamdani, M.S.; Lueong, S.; Schroder, C.; Stang, A.; Hoheisel, J.D. Clinical proteomics: Promises, challenges and limitations of affinity arrays. Proteom. Clin. Appl. 2015, 9, 342-347. [CrossRef] [PubMed]

12. Borrebaeck, C.A.; Wingren, C. Antibody array generation and use. Methods Mol. Biol. 2014, 1131, 563-571. [PubMed]

13. Brennan, D.J.; O'Connor, D.P.; Rexhepaj, E.; Ponten, F.; Gallagher, W.M. Antibody-based proteomics: Fast-tracking molecular diagnostics in oncology. Nat. Rev. Cancer 2010, 10, 605-617. [CrossRef] [PubMed] 
14. Hoheisel, J.D.; Alhamdani, M.S.; Schroder, C. Affinity-based microarrays for proteomic analysis of cancer tissues. Proteom. Clin. Appl. 2013, 7, 8-15. [CrossRef] [PubMed]

15. Schroder, C.; Jacob, A.; Tonack, S.; Radon, T.P.; Sill, M.; Zucknick, M.; Ruffer, S.; Costello, E.; Neoptolemos, J.P.; Crnogorac-Jurcevic, T.; et al. Dual-color proteomic profiling of complex samples with a microarray of 810 cancer-related antibodies. Mol. Cell. Proteom. 2010, 9, 1271-1280. [CrossRef] [PubMed]

16. Wingren, C.; Sandstrom, A.; Segersvard, R.; Carlsson, A.; Andersson, R.; Lohr, M.; Borrebaeck, C.A. Identification of serum biomarker signatures associated with pancreatic cancer. Cancer Res. 2012, 72, 2481-2490. [CrossRef] [PubMed]

17. Ingvarsson, J.; Wingren, C.; Carlsson, A.; Ellmark, P.; Wahren, B.; Engstrom, G.; Harmenberg, U.; Krogh, M.; Peterson, C.; Borrebaeck, C.A. Detection of pancreatic cancer using antibody microarray-based serum protein profiling. Proteomics 2008, 8, 2211-2219. [CrossRef] [PubMed]

18. Schmidt, R.; Jacak, J.; Schirwitz, C.; Stadler, V.; Michel, G.; Marme, N.; Schutz, G.J.; Hoheisel, J.D.; Knemeyer, J.P. Single-molecule detection on a protein-array assay platform for the exposure of a tuberculosis antigen. J. Proteome Res. 2011, 10, 1316-1322. [CrossRef] [PubMed]

19. Alhamdani, M.S.; Schroder, C.; Werner, J.; Giese, N.; Bauer, A.; Hoheisel, J.D. Single-step procedure for the isolation of proteins at near-native conditions from mammalian tissue for proteomic analysis on antibody microarrays. J. Proteome Res. 2010, 9, 963-971. [CrossRef] [PubMed]

20. Smyth, G.K.; Michaud, J.; Scott, H.S. Use of within-array replicate spots for assessing differential expression in microarray experiments. Bioinformatics 2005, 21, 2067-2075. [CrossRef] [PubMed]

21. Alhamdani, M.S.; Youns, M.; Buchholz, M.; Gress, T.M.; Beckers, M.C.; Marechal, D.; Bauer, A.; Schroder, C.; Hoheisel, J.D. Immunoassay-based proteome profiling of 24 pancreatic cancer cell lines. J. Proteom. 2012, 75, 3747-3759. [CrossRef] [PubMed]

22. Nijaguna, M.B.; Schroder, C.; Patil, V.; Shwetha, S.D.; Hegde, A.S.; Chandramouli, B.A.; Arivazhagan, A.; Santosh, V.; Hoheisel, J.D.; Somasundaram, K. Definition of a serum marker panel for glioblastoma discrimination and identification of interleukin 1beta in the microglial secretome as a novel mediator of endothelial cell survival induced by C-reactive protein. J. Proteom. 2015, 128, 251-261. [CrossRef] [PubMed]

23. Botla, S.K.; Gholami, A.M.; Malekpour, M.; Moskalev, E.A.; Fallah, M.; Jandaghi, P.; Aghajani, A.; Bondar, I.S.; Omranipour, R.; Malekpour, F; et al. Diagnostic values of GHSR DNA methylation pattern in breast cancer. Breast Cancer Res. Treat. 2012, 135, 705-713. [CrossRef] [PubMed]

24. Shen, L.; Kondo, Y.; Rosner, G.L.; Xiao, L.; Hernandez, N.S.; Vilaythong, J.; Houlihan, P.S.; Krouse, R.S.; Prasad, A.R.; Einspahr, J.G.; et al. Mgmt promoter methylation and field defect in sporadic colorectal cancer. J. Natl. Cancer Inst. 2005, 97, 1330-1338. [CrossRef] [PubMed]

25. Wolff, E.M.; Chihara, Y.; Pan, F.; Weisenberger, D.J.; Siegmund, K.D.; Sugano, K.; Kawashima, K.; Laird, P.W.; Jones, P.A.; Liang, G. Unique DNA methylation patterns distinguish noninvasive and invasive urothelial cancers and establish an epigenetic field defect in premalignant tissue. Cancer Res. 2010, 70, 8169-8178. [CrossRef] [PubMed]

26. Sato, Y.; Inokuchi, M.; Takagi, Y.; Otsuki, S.; Fujimori, Y.; Yanaka, Y.; Kobayashi, K.; Higuchi, K.; Kojima, K.; Kawano, T. Relationship between expression of IGFBP7 and clinicopathological variables in gastric cancer. J. Clin. Pathol. 2015, 68, 795-801. [CrossRef] [PubMed]

27. Liu, L.; Yang, Z.; Zhang, W.; Yan, B.; Gu, Q.; Jiao, J.; Yue, X. Decreased expression of IGFBP7 was a poor prognosis predictor for gastric cancer patients. Tumour Biol. 2014, 35, 8875-8881. [CrossRef] [PubMed]

28. Rupp, C.; Scherzer, M.; Rudisch, A.; Unger, C.; Haslinger, C.; Schweifer, N.; Artaker, M.; Nivarthi, H.; Moriggl, R.; Hengstschlager, M.; et al. IGFBP7, a novel tumor stroma marker, with growth-promoting effects in colon cancer through a paracrine tumor-stroma interaction. Oncogene 2015, 34, 815-825. [CrossRef] [PubMed]

29. Kim, H.J.; Kang, H.J.; Lee, H.; Lee, S.T.; Yu, M.H.; Kim, H.; Lee, C. Identification of S100A8 and S100A9 as serological markers for colorectal cancer. J. Proteome Res. 2009, 8, 1368-1379. [CrossRef] [PubMed]

30. Fan, B.; Zhang, L.H.; Jia, Y.N.; Zhong, X.Y.; Liu, Y.Q.; Cheng, X.J.; Wang, X.H.; Xing, X.F.; Hu, Y.; Li, Y.A.; et al. Presence of S100A9-positive inflammatory cells in cancer tissues correlates with an early stage cancer and a better prognosis in patients with gastric cancer. BMC Cancer 2012, 12, 316. [CrossRef] [PubMed] 
31. Xu, X.; Chen, H.; Zhu, X.; Ma, Y.; Liu, Q.; Xue, Y.; Chu, H.; Wu, W.; Wang, J.; Zou, H. S100A9 promotes human lung fibroblast cells activation through receptor for advanced glycation end-product-mediated extracellular-regulated kinase 1/2, mitogen-activated protein-kinase and nuclear factor- $\mathrm{B}$-dependent pathways. Clin. Exp. Immunol. 2013, 173, 523-535. [CrossRef] [PubMed]

32. Kwon, C.H.; Moon, H.J.; Park, H.J.; Choi, J.H.; Park do, Y. S100A8 and S100A9 promotes invasion and migration through $\mathrm{p} 38$ mitogen-activated protein kinase-dependent NF- $\mathrm{KB}$ activation in gastric cancer cells. Mol. Cells 2013, 35, 226-234. [CrossRef] [PubMed]

33. Silva, E.J.; Argyris, P.P.; Zou, X.; Ross, K.F.; Herzberg, M.C. S100A8/A9 regulates MMP-2 expression and invasion and migration by carcinoma cells. Int. J. Biochem. Cell Biol. 2014, 55, 279-287. [CrossRef] [PubMed]

34. Sato, T.; Terai, M.; Tamura, Y.; Alexeev, V.; Mastrangelo, M.J.; Selvan, S.R. Interleukin 10 in the tumor microenvironment: A target for anticancer immunotherapy. Immunol. Res. 2011, 51, 170-182. [CrossRef] [PubMed]

35. Szkaradkiewicz, A.; Karpinski, T.M.; Drews, M.; Borejsza-Wysocki, M.; Majewski, P.; Andrzejewska, E. Natural killer cell cytotoxicity and immunosuppressive cytokines (IL-10, TGF- $\beta 1$ ) in patients with gastric cancer. J. Biomed. Biotech. 2010, 2010, 901564. [CrossRef] [PubMed]

36. Couper, K.N.; Blount, D.G.; Riley, E.M. IL-10: The master regulator of immunity to infection. J. Immunol. 2008, 180, 5771-5777. [CrossRef] [PubMed]

37. Itakura, E.; Huang, R.R.; Wen, D.R.; Paul, E.; Wunsch, P.H.; Cochran, A.J. IL-10 expression by primary tumor cells correlates with melanoma progression from radial to vertical growth phase and development of metastatic competence. Mod. Pathol. 2011, 24, 801-809. [CrossRef] [PubMed]

38. Leir, S.H.; Harris, A. MUC6 mucin expression inhibits tumor cell invasion. Exp. Cell Res. 2011, 317, $2408-2419$. [CrossRef] [PubMed]

39. Kufe, D.W. Mucins in cancer: Function, prognosis and therapy. Nat. Rev. Cancer 2009, 9, 874-885. [CrossRef] [PubMed]

40. Zhang, F.G.; He, Z.Y.; Wang, Q. Transcriptome profiling of the cancer and normal tissues from gastric cancer patients by deep sequencing. Tumour Biol. 2014, 35, 7423-7427. [CrossRef] [PubMed]

(C) 2016 by the authors; licensee MDPI, Basel, Switzerland. This article is an open access article distributed under the terms and conditions of the Creative Commons Attribution (CC-BY) license (http://creativecommons.org/licenses/by/4.0/). 